\title{
BMJ Global Health Quality of WHO guidelines on snakebite: the neglect continues
}

\author{
Soumyadeep Bhaumik, ${ }^{1}$ Soushieta Jagadesh, ${ }^{2}$ Zohra Lassi ${ }^{3}$
}

To cite: Bhaumik S, Jagadesh S, Lassi Z. Quality of WHO guidelines on snakebite: the neglect continues. BMJ Glob Health 2018:3:e000783. doi:10.1136/ bmjgh-2018-000783

Handling editor Seye Abimbola

Received 19 February 2018 Revised 18 March 2018 Accepted 24 March 2018

Check for updates

${ }^{1}$ BMJ Global Health, London, UK ${ }^{2}$ UMR Borea, Institut de recherche pour le developpement, Cayenne, French Guiana, France ${ }^{3}$ The Robinson Research Institute, University of Adelaide, Adelaide, South Australia, Australia

\section{Correspondence to} Dr Soumyadeep Bhaumik; drsoumyadeepbhaumik@gmail. com
Snakebite remains a major public health challenge in many parts of rural Africa, Asia and South America. ${ }^{1}$ Available estimates suggest that there are about 94000 deaths across the world annually due to snakebites ${ }^{2}$; a conservative estimate as many deaths in low and middle-income countries are not reported. ${ }^{3}$ The burden on health systems due to snakebite is much higher than what is indicated by the mortality, because even non-venomous snakebite victims visit healthcare facilities for assessment and the morbidity due to snakebite has been scarcely documented. ${ }^{4}$ The social and economic consequences of snakebite are known to be high in communities with high prevalence. ${ }^{5-7}$

Despite its consequences, snakebite has largely been neglected in global health. The WHO readded snakebite to the list of neglected tropical diseases in 2017-potentially implying more attention and funding for disease control programmes and treatment access initiatives. ${ }^{8}$ Such initiatives and programme planning are informed by recommendations in practice guidelines. WHO guidelines are highly influential in South Asia, South-East Asia and sub-Saharan Africa (countries with high burden of snakebite) where the lack of in-country capacity for guideline development means WHO guidelines are used as it is or are being adapted. $^{9}$

It is, therefore, essential to evaluate the quality of WHO guidelines on snakebite. We identified the latest version of the WHO South East Asia Regional Office (SEARO) guideline $(2016)^{10}$ and the WHO Africa Regional Office (AFRO) guideline (2010) by searching the WHO website. ${ }^{11}$ Three authors independently appraised the quality of these guidelines using the Appraisal of Guidelines, Research and Evaluation (AGREE) II, a validated tool for assessing quality of guidelines ${ }^{12}$ via the online data management system available in the AGREE TRUST website (http://www.agreetrust.org/) which blinds the appraisers from each other. The AGREE II has 23 items categorised into six domains and two overall assessment items and
Summary box

Snakebite is a major public health problem in many parts of the world.

- WHO has readded snakebite to the list of neglected tropical diseases in 2017

- The two WHO guidelines on management of snakebite were appraised and found to have poor quality.

- The guidelines had inadequate stakeholder involvement, poor methodological rigour, and competing interests were inadequately managed.

- WHO should ensure development of high-quality guidelines on snakebite management in accordance with the WHO's Guideline Review Committee process.

is widely used for assessing the quality of guidelines including by the WHO. ${ }^{13}$

The quality scores for overall and several key domains of both the WHO guidelines were low (table 1). Scores in the stakeholder development domain were poor $(52 \%$ for the WHO-SEARO 2016 guideline and $31 \%$ for the WHO-AFRO 2010 guideline) due to non-involvement of all categories of health workers, snakebite survivors and their carers in guideline panels. The domain of rigour of development got the lowest scores (15\% for the WHO-SEARO 2016 guideline and $16 \%$ for the WHO-AFRO 2010 guideline) as the guidelines were not based on systematic search, appraisal and grading of evidence. While the WHO-SEARO 2016 guideline has mentioned levels of evidence, these are based on study designs (with no consideration of quality of evidence), with most recommendations are expert opinions. Information on the methodology for formulation of recommendations was also not reported in either of the guidelines. Lack of explicitly reported conflict of interests meant scores in the domain for editorial independence were also poor, and industry representatives were involved in the guideline development process. For the domains of scope and purpose, clarity of presentation and applicability the WHO-SEARO 2016 guideline had better scores than the WHO-AFRO 2010 guideline; however, the scores in both the guidelines 
Table 1 Quality of WHO guidelines on snakebite using AGREE II

\begin{tabular}{|c|c|c|c|c|c|c|c|c|}
\hline \multirow[b]{2}{*}{ Guideline } & Domain 1 & Domain 2 & Domain 3 & Domain 4 & Domain 5 & Domain 6 & \multirow[b]{2}{*}{$\begin{array}{l}\text { Overall } \\
\text { assessment } 1\end{array}$} & \multirow[b]{2}{*}{$\begin{array}{l}\text { Overall } \\
\text { assessment } 2\end{array}$} \\
\hline & $\begin{array}{l}\text { Scope and } \\
\text { purpose } \\
\text { (items 1-3) }\end{array}$ & $\begin{array}{l}\text { Stakeholder } \\
\text { involvement } \\
\text { (items 4-6) }\end{array}$ & $\begin{array}{l}\text { Rigour of } \\
\text { development } \\
\text { (items 7-14) }\end{array}$ & $\begin{array}{l}\text { Clarity of } \\
\text { presentation } \\
\text { (items } \\
15-17 \text { ) }\end{array}$ & $\begin{array}{l}\text { Applicability } \\
\text { (items } \\
\text { 18-21) }\end{array}$ & $\begin{array}{l}\text { Editorial } \\
\text { independence } \\
\text { (items 22-23) }\end{array}$ & & \\
\hline $\begin{array}{l}\text { Guidelines for } \\
\text { the management } \\
\text { of snakebites, } \\
\text { second edition, } \\
2016\end{array}$ & $67 \%$ & $52 \%$ & $15 \%$ & $70 \%$ & $65 \%$ & $3 \%$ & $44 \%$ & $\begin{array}{l}\text { Yes-0; } \\
\text { Yes with } \\
\text { modifications }-3 \text {; } \\
\text { No-0 }\end{array}$ \\
\hline $\begin{array}{l}\text { Guidelines for } \\
\text { the prevention } \\
\text { and clinical } \\
\text { management } \\
\text { of snakebite in } \\
\text { Africa, } 2010\end{array}$ & $54 \%$ & $31 \%$ & $16 \%$ & $50 \%$ & $29 \%$ & $22 \%$ & $33 \%$ & $\begin{array}{l}\text { Yes-0; } \\
\text { Yes with } \\
\text { modifications-0; } \\
\text { No-3 }\end{array}$ \\
\hline
\end{tabular}

Each of the 23 AGREE II items within each of the six domains and the quantitative overall assessment item are rated on a 7-point Likert scale (from 1-strongly disagree to $7-$ strongly agree). The standardised domain quality score is calculated by summing up the scores of all appraisers and standardising by scaling the total as a percentage of the maximum possible score for that domain. The scaled domain score was calculated as: $\{$ (sum of obtained score - minimum possible score) / (maximum possible score - minimum possible score) $\times 100$. The quantitative overall assessment item, which provides the rating of the overall quality of the guideline, is not an aggregate of individual domain scores but an independent item. The qualitative overall assessment item requires the appraiser to judge-whether the guideline might be recommended for use as it is, with modifications or not recommended for use. More details about AGREE II are available at: www.agreetrust. org.

AGREE, Appraisal of Guidelines, Research and Evaluation.

were in the moderate range. Overall, both guidelines were rated poorly.

About a decade ago, the WHO initiated a mechanism to oversee quality assurance through the formation of the Guideline Review Committee in response to public outcry over guidelines being based on expert opinion. ${ }^{14}$ These changes have led to improvements in guideline quality. ${ }^{15}$ However, it appears that these mechanisms are not being implemented or are being bypassed for snakebite guidelines as recently as 2016 . We therefore call on the WHO to strictly implement its own policies for guideline development on snakebite envenoming. Guidelines provide the crucial pivot for action to decrease mortality and morbidity and we call upon the WHO to ensure development of evidence-based snakebite guidelines, involving representative of categories of healthcare workers and snakebite survivors in a transparent manner as is being done for other diseases.

Contributors SB conceptualised the study and searched for guidelines and wrote the first draft of the manuscript. All authors conducted AGREE II appraisals. ZL and SJ revised the manuscript for important intellectual content. All authors agree to final version.

Disclaimer Opinions expressed are those of the authors and not necessarily of their employing organisations.

Competing interests SB and ZL have conducted systematic reviews for informing WHO guidelines for other diseases.

Patient consent Not required.

Provenance and peer review Not commissioned; externally peer reviewed.

Open Access This is an Open Access article distributed in accordance with the Creative Commons Attribution Non Commercial (CC BY-NC 4.0) license, which permits others to distribute, remix, adapt, build upon this work non-commercially, and license their derivative works on different terms, provided the original work is properly cited and the use is non-commercial. See: http://creativecommons.org/ licenses/by-nc/4.0/
(C) Article author(s) (or their employer(s) unless otherwise stated in the text of the article) 2018. All rights reserved. No commercial use is permitted unless otherwise expressly granted.

\section{REFERENCES}

1. Williams DJ. Snake bite: a global failure to act costs thousands of lives each year. BMJ 2015;351:h5378.

2. Kasturiratne A, Wickremasinghe AR, de Silva N, et al. The global burden of snakebite: a literature analysis and modelling based on regional estimates of envenoming and deaths. PLoS Med 2008;5:e218.

3. Bhaumik S. Snakebite: a forgotten problem. BMJ 2013;346:f628.

4. Gutiérrez JM, Burnouf T, Harrison RA, et al. A call for incorporating social research in the global struggle against snakebite. PLoS Negl Trop Dis 2015;9:e0003960.

5. Hasan SM, Basher A, Molla AA, et al. The impact of snake bite on household economy in Bangladesh. Trop Doct 2012;42:41-3.

6. Vaiyapuri S, Vaiyapuri R, Ashokan R, et al. Snakebite and its socioeconomic impact on the rural population of Tamil Nadu, India. PLoS One 2013;8:e80090.

7. Kularatne AM, Silva A, Maduwage K, et al. Victims' response to snakebite and socio-epidemiological factors of 1018 snakebites in a tertiary care hospital in Sri Lanka. Wilderness Environ Med 2014;25:35-40.

8. Gulland A. Sixty seconds on ... snakebite. BMJ 2017;357:j3065.

9. Bhaumik $S$. Use of evidence for clinical practice guideline development. Trop Parasitol 2017;7:65-71.

10. WHO. Guidelines for the management of snake-bites, second edition: World Health Organization, Regional Office for South-East Asia: New Delhi 2016. http://apps.searo.who.int/PDS_DOCS/B5255. pdf?ua $=1$ (accessed on 30th Dec 2017).

11. WHO Regional Office for Africa. Guidelines for the prevention and clinical management of snakebite in Africa: Mauritius 2010. http:// apps.who.int/medicinedocs/documents/s17810en/s17810en.pdf (accessed on 30th Dec 2017).

12. Brouwers MC, Kho ME, Browman GP, et al. Development of the AGREE II, part 2: assessment of validity of items and tools to support application. CMAJ 2010;182:E472-8.

13. WHO. WHO handbook for guideline development. Geneva: World Health Organization, 2014

14. Oxman AD, Lavis JN, Fretheim A. Use of evidence in WHO recommendations. Lancet 2007;369:1883-9.

15. Sinclair D, Isba R, Kredo T, et al. World Health Organization guideline development: an evaluation. PLoS One 2013;8:e63715. 